\title{
Research on Performance Evaluation of Listed Companies in China Based on Factor Analysis and Cluster Analysis
}

\author{
Chenggang Li ${ }^{1}$ Kang Pan ${ }^{1}$ \\ ${ }^{1}$ Faculty of Finance, Guizhou University of Finance and Economics, Guiyang, People's \\ Republic of China
}

\begin{abstract}
This paper choose 2841 listed companies financial data in 2016 from Shanghai Stock Exchange from the RESSET data and build performance evaluation index system with 10 financial indicators. This paper uses factor analysis method to reduce the dimension of the evaluation index in the sample of listed companies and classify the listed companies by cluster analysis method. The number of evaluation index is reduced to 4 from 10, namely: income level, profitability, operation ability, growth ability, the original amount of information from the 4 factors to carry up to $73.387 \%$. According to the contribution rate of the common factors and factor rotation to get The comprehensive evaluation model of financial situation of listed companies in China and use profitability factor in the result of factor analysis as the goal of clustering on listed companies, the clustering result showed that the Chinese listed companies can be divided into 5 categories, grade AAA; grade AA; Grade A; grade B; grade C. This paper has found that there have significant differences in the level of profitability and operational level between grade AA and grade $\mathrm{B}$, not in the level of income and growth ability.
\end{abstract}

\section{Keywords}

Performance Appraisal; Factor Analysis; Cluster Analysis

\section{基于因子分析和聚类分析的中国上市公 司绩效评价研究}

\author{
李成刚 ${ }^{1}$ 潘康 $^{1}$ \\ 1 贵州财经大学金融学院, 贵阳 550025, 中国
}

摘要：本文从 RESSET 金融数据抽取上交所 2841 家上市公司 2016 年财务指标，建立 10 个 财务指标的绩效评价指标体系。本文运用因子分析法对样本中上市公司的评价指标进行降维 处理; 运用聚类分析法将样本中上市公司进行分类。通过因子分析方法将 10 个评价指标降维 成 4 个, 分别是:收益水平、盈利能力、营运能力、成长能力, 该 4 个公因子携带原始信息量 达 $73.387 \%$ ；依据公因子的贡献率及旋转后的因子值得到中国上市企业财务状况的综合评价 模型。并且以因子分析的中盈利因子为目标对上市公司进行聚类,聚类结果显示，中国上市企 业可划分为 5 类分别分为 AAA 级、AA 级、A 级、B 级、C 级, 并将 AA 级和 B 级企业进行 
检验, 发现这两类企业在盈利水平和营运水平上有显著差异, 在收益水平和成长能力方面差 异不显著。

关键词: 绩效评价; 因子分析; 聚类分析

\section{1. 引言}

所中国经历了十几年的高速发展， 上市公司作为经济的主要支撑力量, 已 经成为金融领域研究的热门问题。中国 各行 各业的上市公司聚集了优质资源 并推动国民经济的快速发展; 所以, 在 国际市场竞争中充当中坚力量的上市 公司的发展关系到国家竞争力的大小。 上市公司的经营绩效直接的反映了国 家经济发展的水平。上市公司的经营绩 效受诸多因素的影响, 如宏观方面的政 府政策、地理位置和宏观经济; 微观方 面有企业资本结构、技术及股利分配政 策等因素的影响, 因此, 构建科学的指 标体系并合理地评价中国上市公司经 营绩效, 可以更准确地分析中国上市公 司的经营绩效，进而为中国上市企业的 竞争力及可持续发展能力的提升提供 了可靠的数据支持, 对中国经济的稳定 发展具有重要的现实意义。

\section{2. 文献回顾}

张涛等 ${ }^{[1]}$ 选取深市 84 家上市公司 2010 年-2011 年相关数据为样本, 对风 险企业上市公司的经营绩效进行比较 分析, 以便为风险企业进行风险投资提 供决策支持。赵欣 ${ }^{[2]}$ 选取 A、B 两股 98 家上市公司的 14 个财务指标并构建 2011-2013 年面板数据运用因子分析方 法对 A、B 两股的上市公司进行对比, 结果表明在盈利能力、偿债能力和成长 能力方面 $\mathrm{A}$ 股上市公司均优于 $\mathrm{B}$ 股上 市公司, 并对两类股上市公司提出了发 展建议。李启平 ${ }^{[3]}$ 基于盈利能力方面利
用 2010-2014 年房地产上市公司的财务 数据分析了中国房地产行业上市公司 绩效问题，实证结果表明：政府政策对 上市企业绩效有显著影响; 企业规模经 济有助于提高企业绩效; 成本费用对企 业绩效具有显著影响, 依据结果为上市 公司的发展提供了合理建议。纪汉霖 ${ }^{[4]}$ 利用 2013-2015 年中国家电行业和电力 行业上市公司财务数据构建评价指标 体系, 研究发现: 在经营绩效方面如盈 利能力、偿债能力、成长能力等, 家电 行业上市公司优于电力行业上市公司; 在企业绩效方面, 由于经济环境、企业 的规模及资本结构等因素影响, 家电和 电力行业存在显著差异。王蕾 ${ }^{[5]}$ 利用 2012 2014 年中国农业 37 家上市公司 的财务数据构建指标评价体系, 通过因 子分析法进行实证研究。研究结果表 明: 中国农业上市公司绩效水平呈现出 “两头小，中间大”，其中，盈利能力和 偿债能力是影响中国农业上市公司绩 效水平高低的主要因素, 并且, 还指出 中国农业上市公司绩效水平偏低。叶会 [6]选取 219 家民营化上市公司作为样 本, 通过因子分析法分离出反映公司绩 效的盈利质量因子, 透过盈利质量因子 进行实证分析, 实证结果与以盈利水平 来衡量绩效的结果相反, 发现: 民营化 并没有改善公司业绩, 反而下降, 竞争 性的国有控股上市公司盈利质量下降 更显著, 国有控股作用也不一定是消极 的。蔚利芝[7]选取 2011 2014 年沪深两 市 77 家上市公司报数据, 运用因子分 析法分析了银行借款、债券融资和股权 融资对上市公司绩效的影响, 研究发 现：银行借款对上市公司绩效水平具有 
负面影响，而债券融资和股权融资对上 市公司绩效水平具有正向影响, 并且提 出调整融资结构对提升中国上市公司 绩效水平具有重大意义。刘畅 ${ }^{[8]}$ 运用因 子分析方法分析了 150 家中国上市公司 的并购前后的绩效，研究发现：随时间 的推移, 并购对于提高中国上市企业绩 效越来越明显, 并针对中国上市公司在 并购市场出现的问题提出了一些建议。

综上所述, 目前国内学者们对中国 各个产业的上市公司经营绩效研究已 经非常成熟，通过产业内上市公司对比 及跨产业上市公司的对比给出了各个 产业上市公司提高经营绩效的政策建 议，本文对中国上市公司进行实证结果 验证, 与学者前辈们所得结论基本吻 合。

\section{3. 模型介绍}

\section{1. 因子分析模型}

因子分析（Factor Analysis）模型基 于主成分分析法的一种推广。通过研究 变量矩阵的内部关系, 把多数变量中具

有相关关系的变量归为一类达到降维

的目的, 因子模型可具体写成:

$$
\left\{\begin{array}{c}
x_{1}=a_{11} f_{1}+a_{12} f_{2}+. .+a_{1 m} f_{m}+a_{1} \varepsilon_{1} \\
x_{2}=a_{21} f_{1}+a_{22} f_{2}+. .+a_{2 n} f_{m}+a_{2} \varepsilon_{1} \\
\ldots \\
x_{p}=a_{p 1} f_{1}+a_{p 2} f_{2}+. .+a_{p n} f_{m}+a_{p} \varepsilon_{1}
\end{array}\right.
$$

式中, $f_{1}, f_{2}, \ldots, f_{m}$ 为公因子, 反映 某方面信息的潜在变量; $a_{i j}$ 为因子载荷 系数, 是第 $i$ 个指标在第 $j$ 个因子上的 负荷。

\section{2. 聚类分析模型}

聚类，即所谓“物以类聚”，它是按 某种相似规则对给定样本集、指标族进 行某种性质的划分, 将集合中的若干样
本划分为若干类。

将数据抽象化为样本矩阵 $X=\left(X_{i j}\right)_{n \times m}, X_{i j}$ 表示第 $i$ 个样本的第 $j$ 个 变量的值. 聚类目的, 就是从数据出发, 将样本或变量分成类, 欧式距离越小表 示他们越相似, 距离公式如下所示:

$$
d_{i j}=\sqrt{\sum_{k=1}^{p}\left(X_{i k}-X_{j k}\right)^{2}}
$$

\section{4. 实证分析}

\section{1. 样本选取}

本文数据来自 RESSET 金融数据库 的上海证券交易所公布的公司年报数 据。样本集选取了 2016 年中国 2841 家 上市公司的财务数据。

\section{2. 指标体系的确定}

评价指标体系构建的合理及正确 性, 会直接影响模型实证分析结果的准 确性。因此, 本文在进行实证分析时, 借鉴国家财政部发布的企业绩效评价 体系, 选择了 10 个指标, 它们分别是: 每股收益、每股营业利润、销售净利率、 流动比率、营业利润率、营业收入增长 率、净资产增长率、财务费用率、管理 费用率、每股营业总收入。

\section{3. 因子分析过程}

KMO(Kaiser-Meyer-Olkin)检验值 为 0.554 , 大于 0.5 说明本模型构建合 理, Bartlett 球形检验显著性为 0 小于 0.05 , 拒绝变量之间不相关的原假设, 接受备择假设, 可以考虑因子分析, 检 验数据如表 1 所示。

表 1KM0 与 Bartlett 检验

\begin{tabular}{|c|c|c|}
\hline $\begin{array}{r}\text { Kaiser-Meyer-01kin 测 } \\
\text { 量取样适当性 }\end{array}$ & 0.554 \\
\hline \multirow{2}{*}{$\begin{array}{c}\text { Bart1ett 球 } \\
\text { 形检验 }\end{array}$} & 卡方 & 15982.791 \\
\cline { 2 - 3 } & df & 45 \\
\cline { 2 - 3 } & 显著性 & 0 \\
\hline
\end{tabular}


该表是公因子方差比表, 撷取数值 表示对应的变量信息被公因子提出的 比例, 未提取的数值由特殊因子解释, 数值如表所示。

表 2 公因子方差比

\begin{tabular}{|c|c|c|}
\hline & 起始 & 擷取 \\
\hline 每股收益 & 1.000 & 0.825 \\
\hline 每股营业利润 & 1.000 & 0.910 \\
\hline 销售净利率 & 1.000 & 0.934 \\
\hline 流动比率 & 1.000 & 0.699 \\
\hline 营业利润率 & 1.000 & 0.916 \\
\hline 营业收入增长率 & 1.000 & 0.629 \\
\hline 净资产增长率 & 1.000 & 0.619 \\
\hline 财务费用率 & 1.000 & 0.741 \\
\hline 管理费用率 & 1.000 & 0.543 \\
\hline 每股营业总收入 & 1.000 & 0.523 \\
\hline
\end{tabular}

本文提取 4 个公因子，其中公因子 1 的起始特征值为 2.54 , 说明该公因子 携带信息相当于 2.54 个原始变量, 代表 信息浓缩, 对于小于 1 的数据则剔除, 4 个公因子累计携带信息为 $73.387 \%$ 。

表 3 变异数总计

\begin{tabular}{|c|c|c|c|}
\hline \multirow{2}{*}{ 元件 } & \multicolumn{3}{|c|}{ 起始特征值 } \\
\hline & 总计 & 变异 $(\%)$ & 累加 (\%) \\
\hline 1 & 2.54 & 25.398 & 25.398 \\
\hline 2 & 2.187 & 21.868 & 47.267 \\
\hline 3 & 1.376 & 13. 758 & 61.025 \\
\hline 4 & 1. 236 & 12.363 & 73.387 \\
\hline 5 & 0.765 & 7.655 & 81.042 \\
\hline 6 & 0.676 & 6.757 & 87.799 \\
\hline 7 & 0.633 & 6.327 & 94.125 \\
\hline 8 & 0.444 & 4.437 & 98.562 \\
\hline 9 & 0.123 & 1.226 & 99.788 \\
\hline 10 & 0.021 & 0.212 & 100 \\
\hline \multirow{2}{*}{ 元件 } & \multicolumn{3}{|c|}{ 擷取平方和载入 } \\
\hline & 总计 & 变异 $(\%)$ & 累加 (\%) \\
\hline 1 & 2.54 & 25.398 & 25.398 \\
\hline 2 & 2. 187 & 21.868 & 47.267 \\
\hline 3 & 1. 376 & 13.758 & 61.025 \\
\hline 4 & 1.236 & 12.363 & 73. 387 \\
\hline \multirow{2}{*}{ 元件 } & \multicolumn{3}{|c|}{ 循环平方和载入 } \\
\hline & 总计 & 变异（\%） & \\
\hline 1 & 2.441 & 24.41 & \\
\hline 2 & 2.195 & 21.949 & \\
\hline 3 & 1.46 & 14.602 & \\
\hline 4 & 1. 243 & 12.426 & \\
\hline
\end{tabular}

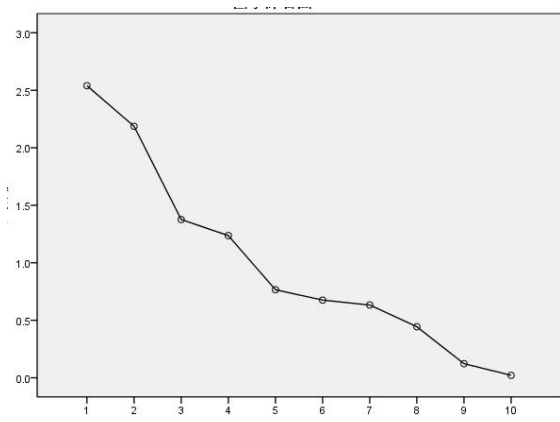

图 1 因子碎石图

本文通过碎石图直观的反应了 4 个 公因子的重要性。特征值大于 1 的点有 4 个, 碎石图是降序的、与因子关联的 特征值以及因子的数量, 它可以直观评 估哪些因子占数据中变异性的大部分。

通过最大方差旋转得到因子负荷, 对比公因子矩阵, 旋转后使得公因子差 距更大, 更容易分类, 通过该表可以得 知, 营业利润率、销售净利率、财务费 用率三变量在公因子 1 中数值较高则公 因子 FAC1 表示收益水平因子, 以此类 推 FAC2 表示盈利因子; FAC3 表示营 运因子; FAC4 表示成长因子。

\begin{tabular}{|c|c|c|c|c|}
\hline & \multicolumn{4}{|c|}{ 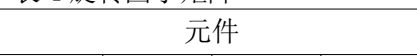 } \\
\hline & FAC1 & FAC2 & FAC3 & FAC4 \\
\hline 营业利润率 & 0.936 & 0.125 & 0.154 & -0.001 \\
\hline 销售净利率 & 0.935 & 0.114 & 0.217 & 0.002 \\
\hline 财务费用率 & 0.712 & -0.186 & -0.447 & 0.001 \\
\hline 每股营业利润 & 0.085 & 0.950 & 0.012 & -0.020 \\
\hline 每股收益 & 0.097 & 0.895 & 0.119 & 0.000 \\
\hline $\begin{array}{c}\text { 每股营业总收 } \\
\text { 入 }\end{array}$ & -0.127 & 0.619 & -0.338 & 0.093 \\
\hline 流动比率 & -0.033 & 0.039 & 0.834 & 0.023 \\
\hline 管理费用率 & 0.387 & -0.203 & 0.593 & -0.014 \\
\hline $\begin{array}{c}\text { 营业收入增长 } \\
\text { 率 }\end{array}$ & -0.008 & 0.000 & -0.081 & 0.789 \\
\hline 净资产增长率 & 0.009 & 0.038 & 0.086 & 0.781 \\
\hline
\end{tabular}




\section{4. 聚类分析过程}

本文将 2841 家上市企业按盈利能 力进行聚类分为 5 类企业, 分别是 $\mathrm{AAA}$ 级、 $\mathrm{AA}$ 级、 $\mathrm{A}$ 级、 $\mathrm{B}$ 级、 $\mathrm{C}$ 级分别对 应聚类中心 4、聚类中心 1 、聚类中心 5 、 聚类中心 $2 、$ 聚类中心 3 , 聚类中心数 值如表 5 所示。

表 5 最终聚类中心

\begin{tabular}{|c|c|c|c|c|}
\hline \multicolumn{5}{|c|}{ 聚集 } \\
\hline 1 & 2 & 3 & 4 & 5 \\
\hline 4.25 & 0.18 & -0.61 & 14.28 & 1.5 \\
\hline
\end{tabular}

其中盈利能力在 AAA 级的上市企 业有 2 家, AA 级的上市企业有 43 家, A 级上市企业有 324 家、B 级上市企业 有 1018 家、C 级上市企业有 1454 家, 数据如表 6 所示。

表 6 聚类后企业数量

\begin{tabular}{|c|c|c|}
\hline \multirow{2}{*}{ 聚集 } & 1 & 43.000 \\
\cline { 2 - 3 } & 2 & 1018.000 \\
\cline { 2 - 3 } & 3 & 1454.000 \\
\cline { 2 - 3 } & 4 & 2.000 \\
\cline { 2 - 3 } & 5 & 324.000 \\
\hline \multicolumn{2}{|c|}{ 有效 } & 2841.000 \\
\hline \multicolumn{2}{|c|}{ 遗漏 } & 0.000 \\
\hline
\end{tabular}

\section{5. 独立样本 $\mathrm{T}$ 检验}

本文对 $\mathrm{AA}$ 类与 $\mathrm{B}$ 类企业四个公因 子进行独立样本 $\mathrm{T}$ 检验, 检验结果如表 7 所示, 检验结果分析如下:

收益水平差异分析： AA 类与 B 类 $\mathrm{F}$ 统计量的 Sig 值 0.98 大于 0.05 , 不能 否认方差齐性的 Levene 检验, 参考第 一行数据, 可以得出 $\mathrm{T}$ 检验双侧 $\mathrm{Sig}$ 值 0.489 大于 0.05 , 即在 0.05 显著水平上 两类企业的收益水平并无显著差异。

盈利水平差异分析： $\mathrm{AA}$ 类与 $\mathrm{B}$ 类 $\mathrm{F}$ 统计量的 $\mathrm{Sig}$ 值 0.000 小于 0.05 , 否 认方差齐性的 Levene 检验, 参考第二 行数据, 可以得出 $\mathrm{T}$ 检验双侧 $\mathrm{Sig}$ 值 0.000 小于 0.05 , 即在 0.05 显著水平上 两类企业的盈利水平存在显著差异。
营运水平差异分析： AA 类与 B 类 $\mathrm{F}$ 统计量的 Sig 值 0.014 小于 0.05 , 否 认方差齐性的 Levene 检验, 参考第二 行数据, 可以得出 $\mathrm{T}$ 检验双侧 $\mathrm{Sig}$ 值 0.048 小于 0.05 , 即在 0.05 显著水平上 两类企业的营运水平存在显著差异。

成长水平差异分析: $\mathrm{AA}$ 类与 $\mathrm{B}$ 类 $\mathrm{F}$ 统计量的 $\mathrm{Sig}$ 值 0.533 大于 0.05 , 不 能否认方差齐性的 Levene 检验, 参考 第一行数据, 可以得出 $\mathrm{T}$ 检验双侧 $\mathrm{Sig}$ 值 0.803 大于 0.05 , 即在 0.05 显著水平 上两类企业的成长水平并无显著差异。

表 7 独立样本检验（ $a=0.05 ）$

\begin{tabular}{|c|c|c|c|c|}
\hline \multirow{2}{*}{\multicolumn{2}{|c|}{ 公因子 }} & \multicolumn{3}{|c|}{ Levene 变异数相等测试 } \\
\hline & & \multirow{2}{*}{$\frac{F}{0.001}$} & \multirow{2}{*}{$\begin{array}{c}\text { 显著性 } \\
0.98\end{array}$} & \\
\hline 收益水平 & $\mathrm{Y}$ & & & \\
\hline & $\mathrm{N}$ & & & \\
\hline 盈利能力 & $\mathrm{Y}$ & 695.453 & 0 & \\
\hline & $\mathrm{N}$ & & & \\
\hline 营运能力 & $\mathrm{Y}$ & 6.116 & 0.014 & \\
\hline & $\mathrm{N}$ & & & \\
\hline 成长能力 & $\mathrm{Y}$ & 0.389 & 0.533 & \\
\hline & $\mathrm{N}$ & & & \\
\hline & & 针对平均 & 是否相等 & 约 $\mathrm{T}$ 检验 \\
\hline 公因子 & & $\mathrm{T}$ & $\mathrm{df}$ & $\begin{array}{l}\text { 显著性 } \\
\text { (双尾) }\end{array}$ \\
\hline 收益水平 & $\mathrm{Y}$ & -0.692 & 1058 & 0.489 \\
\hline & $\mathrm{N}$ & -1.913 & 86.484 & 0.059 \\
\hline 盈利能力 & $\mathrm{Y}$ & 70.764 & 1058 & 0 \\
\hline & $\mathrm{N}$ & 21.581 & 41.179 & 0 \\
\hline 营运能力 & $\mathrm{Y}$ & -2.718 & 1058 & 0.007 \\
\hline & $\mathrm{N}$ & -2.031 & 42.811 & 0.048 \\
\hline 成长能力 & $\mathrm{Y}$ & -0.249 & 1058 & 0.803 \\
\hline & $\mathrm{N}$ & -0.267 & 45.029 & 0.79 \\
\hline
\end{tabular}

（注: Y 表示采用相等变异数; $\mathrm{N}$ 表示不采用相等 变异数)

\section{5. 结论与建议}

通过对比 $\mathrm{AA}$ 类与 $\mathrm{B}$ 类上市企业四 个因子, 盈利能力与营运能力存在显著 差异, 收益水平与成长能力差异不明 显, 所以在盈利能力与营运能力方面, 
B 类企业逊色于 AA 类企业。针对这种 现状提出如下建议。

1.突出主营业务, 提高企业的盈利 能力。以盈利为导向的经营特点, 公司 将人力、物力等资源集中于主营业务, 可以提高盈利财务指标，增强上市企业 盈利能力。

2.加大研发投入，提高企业创新能 力。上市企业应当充分利用资金，引导 资金流向创新项目, 从长期来看, 这样 的做法可以大大提高企业竞争力, 促使 上市企业形成更加完善、高效的技术创 新体系。

3.加强融资市场科学管理, 由市场 的力量引导。上市公司应根据自身的实 际情况制定融资方案, 股权融资和债券 融资双管齐下, 为上市公司运营提供充 分资金保障，间接地提高了上市公司绩 效水平。

\section{参考文献}

[1] 张涛,程文丽,李漫漫, 风险企业绩效 评价指标体系研究一以我国中小板 风险为例,经济与管理评论, 3 : 15-20, 2014.

[2] 赵欣, 中国境内主板上市公司绩效 与影响因素分析——基于 $\mathrm{A} 、 \mathrm{~B}$ 股 相关上市公司的对比,经济管理, 3: 180-189, 2015.

[3] 李启平, 盛晓静,胡椰姣, 盈利能力视 角下我国房地产行业上市公司绩效 的影响因素分析,湖南科技大学学报 (自然科学版), 1: 107-111, 2016.

[4] 纪汉霖,周金华, 不同行业的上市公 司绩效与影响因素对比分析一以 家电行业与电力行业为例,哈尔滨商 业大学学报 (社会科学版), 3: 61-70, 2016.

[5] 王蕾,刘慧萍, 基于因子分析法的中 国农业上市公司绩效评价,经济研究 参考, 56: $25-29+50,2016$.
[6] 叶会,季风梁,程晓，民营化改善公司 绩效了吗? 一一基于盈利质量视角 的分析,会计与经济研究, 6: 30-45, 2016.

[7] 蔚利芝, 郭淑娟, 融资结构对上市公 司绩效的影响研究,财会通讯, 8: 46-49, 2016.

[8] 刘畅,韩爱华,沈锡茜, 基于因子分析 法的上市公司并购绩效评价,统计与 决策, 10: 179-181, 2017. 